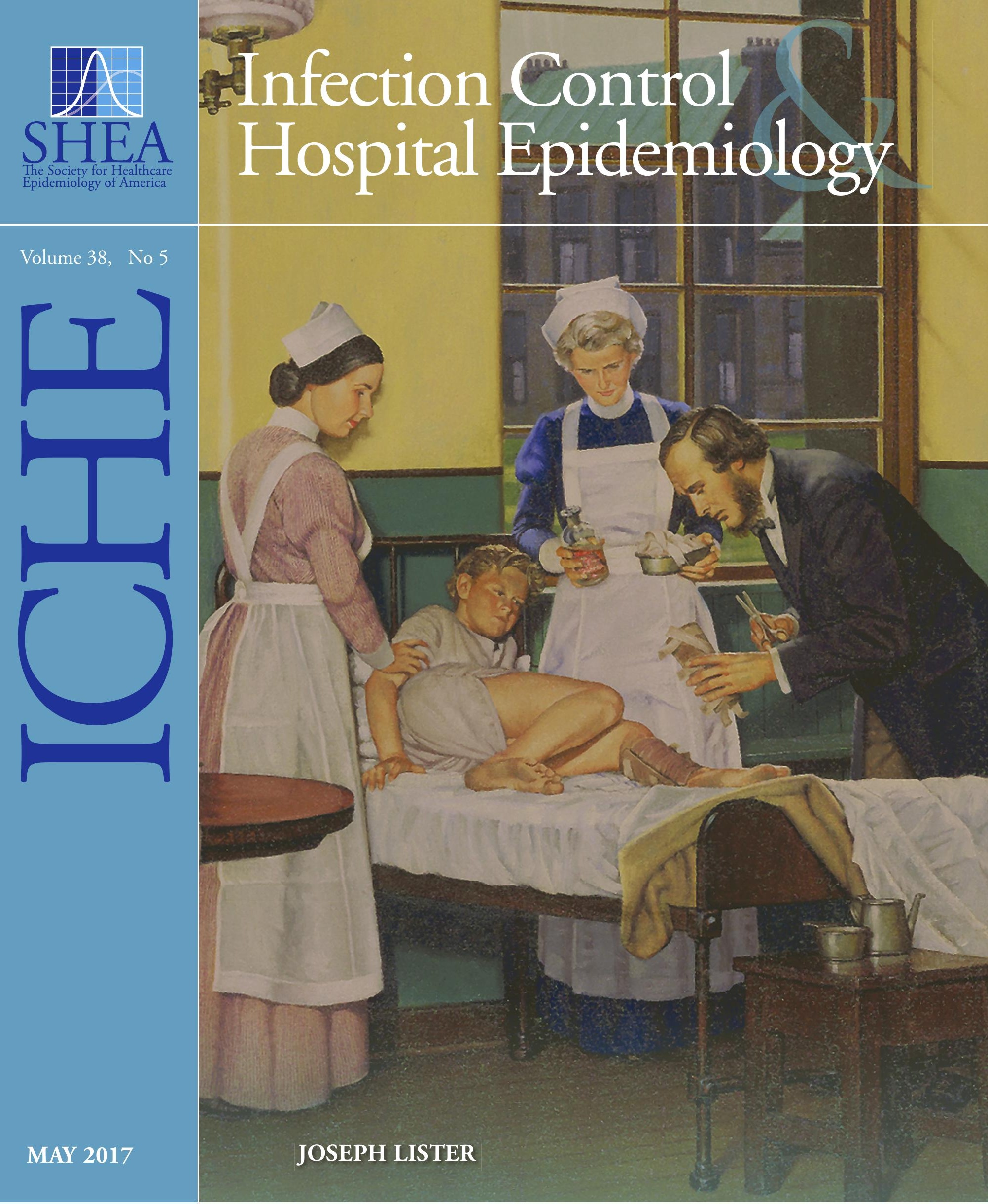




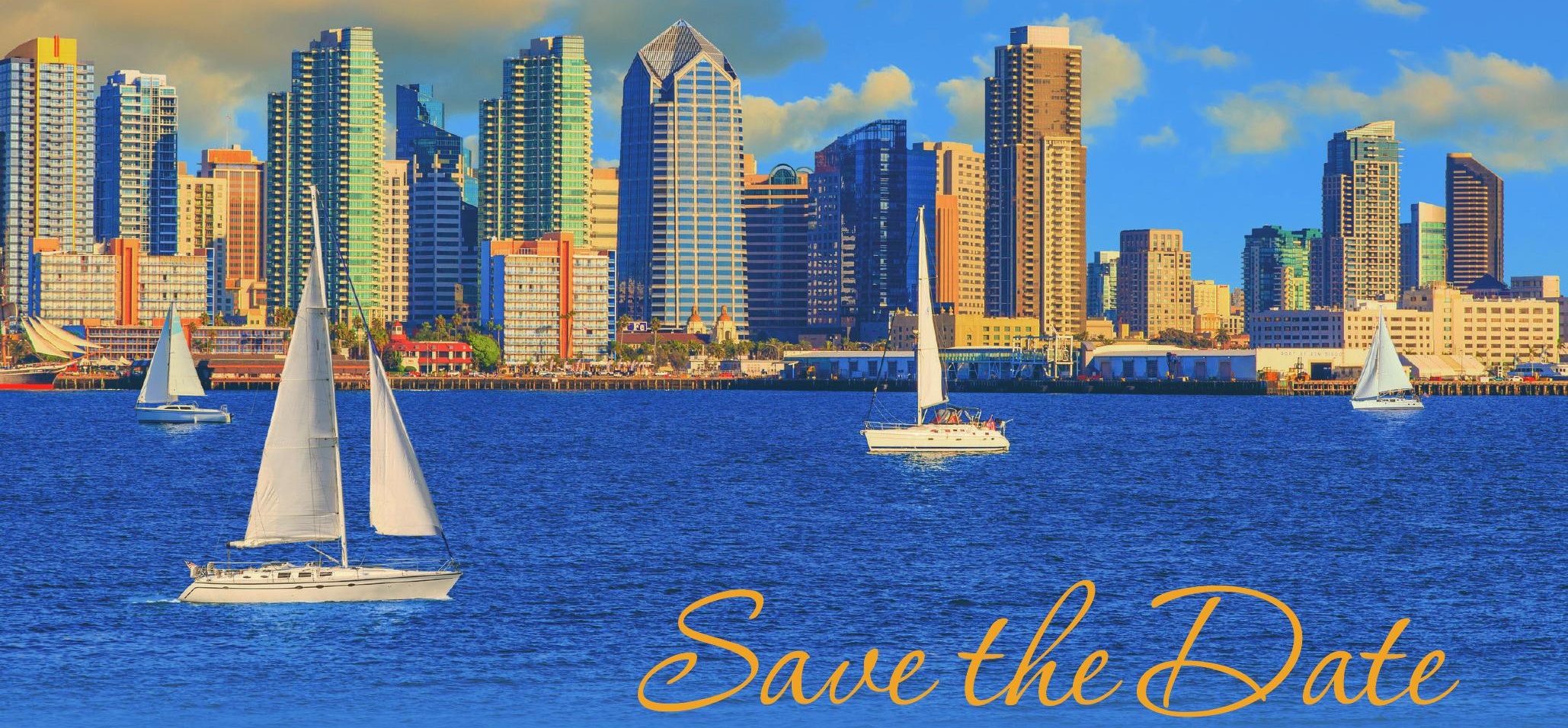

\section{Don't miss}

the premier

international

infectious

diseases

meeting of

the year

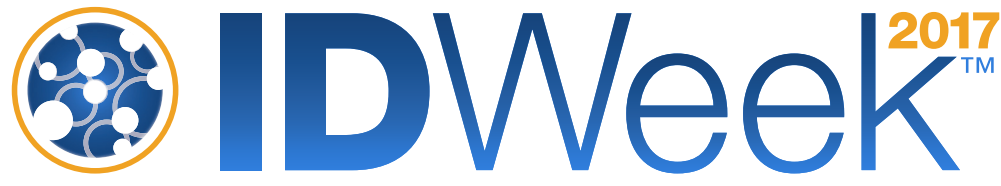

Advancing Science, Improving Care

October 4-8, 2017

San Diego, CA

www.idweek.org

\section{A JOINT MEETING OF}




\section{CONTENTS}

\section{Original Articles}

513 A Report of the Efforts of the Veterans Health Administration National Antimicrobial Stewardship Initiative Allison A. Kelly, Makoto M. Jones, Kelly L. Echevarria, Stephen M. Kralovic, Matthew H. Samore, Matthew B. Goetz, Karl J. Madaras-Kelly, Loretta A. Simbartl, Anthony P. Morreale, Melinda M. Neuhauser and Gary A. Roselle

521 Commentary: Improving Patient Safety Through Antibiotic Stewardship: The Veterans Health Administration Leads the Way, Again Arjun Srinivasan and Lisa E. Davidson

524 Urine Culture Testing in Community Nursing Homes: Gateway to Antibiotic Overprescribing Philip D. Sloane, Christine E. Kistler, David Reed, David J. Weber, Kimberly Ward and Sheryl Zimmerman

532 Commentary: Applying the Horizontal and Vertical Paradigm to Antimicrobial Stewardship Payal K. Patel

534 Intervention to Reduce Broad-Spectrum Antibiotics and Treatment Durations Prescribed at the Time of Hospital Discharge: A Novel Stewardship Approach Norihiro Yogo, Katherine Shihadeh, Heather Young, Susan L. Calcaterra, Bryan C. Knepper, William J. Burman, Philip S. Mehler and Timothy C. Jenkins

542 The Use of a Computerized Provider Order Entry Alert to Decrease Rates of Clostridium difficile Testing in Young Pediatric Patients Maribeth R. Nicholson, Peter N. Freswick, M. Cecilia Di Pentima, Li Wang, Kathryn M. Edwards, Gregory J. Wilson and Thomas R. Talbot

547 Hand Hygiene With Alcohol-Based Hand Rub: How Long Is Long Enough? Daniela Pires, Hervé Soule, Fernando Bellissimo-Rodrigues, Angèle Gayet-Ageron and Didier Pittet

553 Assessing the Likelihood of Hand-to-Hand Cross-Transmission of Bacteria: An Experimental Study Fernando Bellissimo-Rodrigues, Daniela Pires, Hervé Soule, Angèle Gayet-Ageron and Didier Pittet

559 National Automated Surveillance of Hospital-Acquired Bacteremia in Denmark Using a Computer Algorithm Sophie Gubbels, Jens Nielsen, Marianne Voldstedlund, Brian Kristensen, Henrik C. Schфnheyder, Svend Ellermann-Eriksen, Jørgen H. Engberg, Jens K. Mфller, Christian Østergaard and Kåre Mфlbak

567 An Outbreak of Burkholderia cepacia Complex Infections Associated with Contaminated Liquid Docusate Lucila Marquez, Katie N. Jones, Elaine M. Whaley, Tjin H. Koy, Paula A. Revell, Ruston S. Taylor, M. Brooke Bernhardt, Jeffrey L. Wagner, James J. Dunn, John J. LiPuma and Judith R. Campbell

574 Comparing External Ventricular Drains-Related Ventriculitis Surveillance Definitions Maria M. Reyes, Satish Munigala, Emily L. Church, Tobias B. Kulik, Salah G. Keyrouz, Gregory J. Zipfel and David K. Warren

\section{Review Article}

580 Carbapenem-Resistant Enterobacteriaceae: A Strategic Roadmap for Infection Control N. Deborah Friedman, Yehuda Carmeli, Aaron Lea Walton and Mitchell James Schwaber 


\section{Concise Communications}

595 A Randomized Trial to Determine the Impact of an Educational Patient Hand-Hygiene Intervention on Contamination of Hospitalized Patient's Hands with Healthcare-Associated Pathogens Venkata C. K. Sunkesula, Sirisha Kundrapu, Shanina Knighton, Jennifer L. Cadnum and Curtis J. Donskey

598 Pseudo-outbreak of Brevundimonas diminuta Attributed to Contamination of Culture Medium Supplement Rachael A. Lee, Stephen A. Moser, Martha Long, Susan L. Butler, Jennifer F. Whiddon and Bernard C. Camins

602 Lack of Benefit With Combination Therapy for Clostridium difficile Infection Jessica C. Njoku, Trevor C. Van Schooneveld, Mark E. Rupp, Keith M. Olsen, Fang Qiu, Jane L. Meza and Elizabeth D. Hermsen

606 Disability Adjusted Life Year (DALY) of Central-Line Bloodstream Infection (CLABSI) in a University Hospital in a Developing Country, Brazil Jaqueline Abel da Rocha, Fernanda Moreth do Valle, Natalia Chilinque Zambão da Silva, Ana Sheila Duarte Nunes Silva, Suzana dos Santos Vaz, Wildo Navegantes de Araújo and Ianick Souto Martins

610 A Practical Tool for Surveillance of Surgical-Site Infections: A 5-Year Experience in Orthopedic Surgeries Shmuel Benenson, Allon E. Moses, Matan J. Cohen, Meir Brezis, Naomi Minster, Carmela Schwartz, Leonid Kandel, Meir Liebergall and Yoav Mattan

614 Challenges to Safe Injection Practices in Ambulatory Care Laura Anderson, Benjamin Weissburg, Kelli Rogers, Jackson Musuuza, Nasia Safdar and Daniel Shirley

\section{Research Briefs}

617 Alcohol Caps or Alcohol Swabs With and Without Chlorhexidine: An In Vitro Study of 648 Episodes of Intravenous Device Needleless Connector Decontamination Julie M. Flynn, Claire M. Rickard, Samantha Keogh and Li Zhang

619 Reinstatement of Reflex Testing of Stool Samples for Vancomycin-Resistant Enterococci (VRE) Resulted in Decreased Incidence of Hospital-Associated VRE

Satish Munigala, Kathleen M. McMullen, Anthony J. Russo, S. Reza Jafarzadeh, Joan Hoppe-Bauer, Carey-Ann D. Burnham and David K. Warren

621 Impact of Changes to the National Healthcare Safety Network (NHSN) Definition on Catheter-Associated Urinary Tract Infection (CAUTI) Rates in Intensive Care Units at an Academic Medical Center Sonali D. Advani, Rachael A. Lee, Mariann Schmitz and Bernard C. Camins

623 Analysis of Bed Bug (Cimex lectularius) Introductions Into an Academic Medical Center Johnathan Michael Sheele, Erika Barrett, Obada Farhan and Nathan Morris

\section{Letters to the Editor}

625 A Response to the Validity of an Article Reporting Contrary Cleaning Efficacy Results for Robotic Surgical Instruments Brian H. Wallace

626 Emergency Evacuation of Immunocompromised Patients From a Hematology Unit Following Flooding of High-Efficiency Particulate Air (HEPA) Filtration Philippe Saliou, Jean-Christophe Ianotto, Marie-Anne Couturier, Gaëlle Guillerm, Hervé Le Bars, Dorothée Quinio, Solène Le Gal and Raoul Baron

629 Attire as a Fomite: Proposal for a New Index Concerning Change of Attire Richard Pougnet and Laurence Pougnet

630 Multidrug-Resistant Organisms in the Rooms of Patients in Healthcare Facilities Farrin A. Manian 
631 An Observational Study to Compare Oral Hygiene Care With Chlorhexidine Gluconate Gel Versus Mouthwash to Prevent Ventilator-Associated Pneumonia Hung-Jen Tang, Chien-Ming Chao, Pak-On Leung and Chih-Cheng Lai

632 Does Second Place Count? Lessons from a Major Discrepancy Between Carbapenem-Resistant Klebsiella pneumoniae and Carbapenem-Resistant Enterobacter cloacae in a One-Year Follow-Up Study Leandro Reus Rodrigues Perez.

634 Characterization of Transformants Obtained From NDM-1-Producing Enterobacteriaceae in Brazil Franciéli P. Rozales, Cibele M. Magagnin, Juliana C. Campos, Mariana Pagano, Luciana S. Nunes, Lisiane R. Pancotto, Jorge L. M. Sampaio, Alexandre P. Zavascki and Afonso L. Barth

636 Is AGREE II a counsel of perfection? A letter commenting on Lytvyn et al Sheldon P. Stone, Mark Wilcox and Peter Hawkey 


\section{CAMBRIDGE}

\section{Medicine}

\section{OUT NOW!}

MOLECULAR
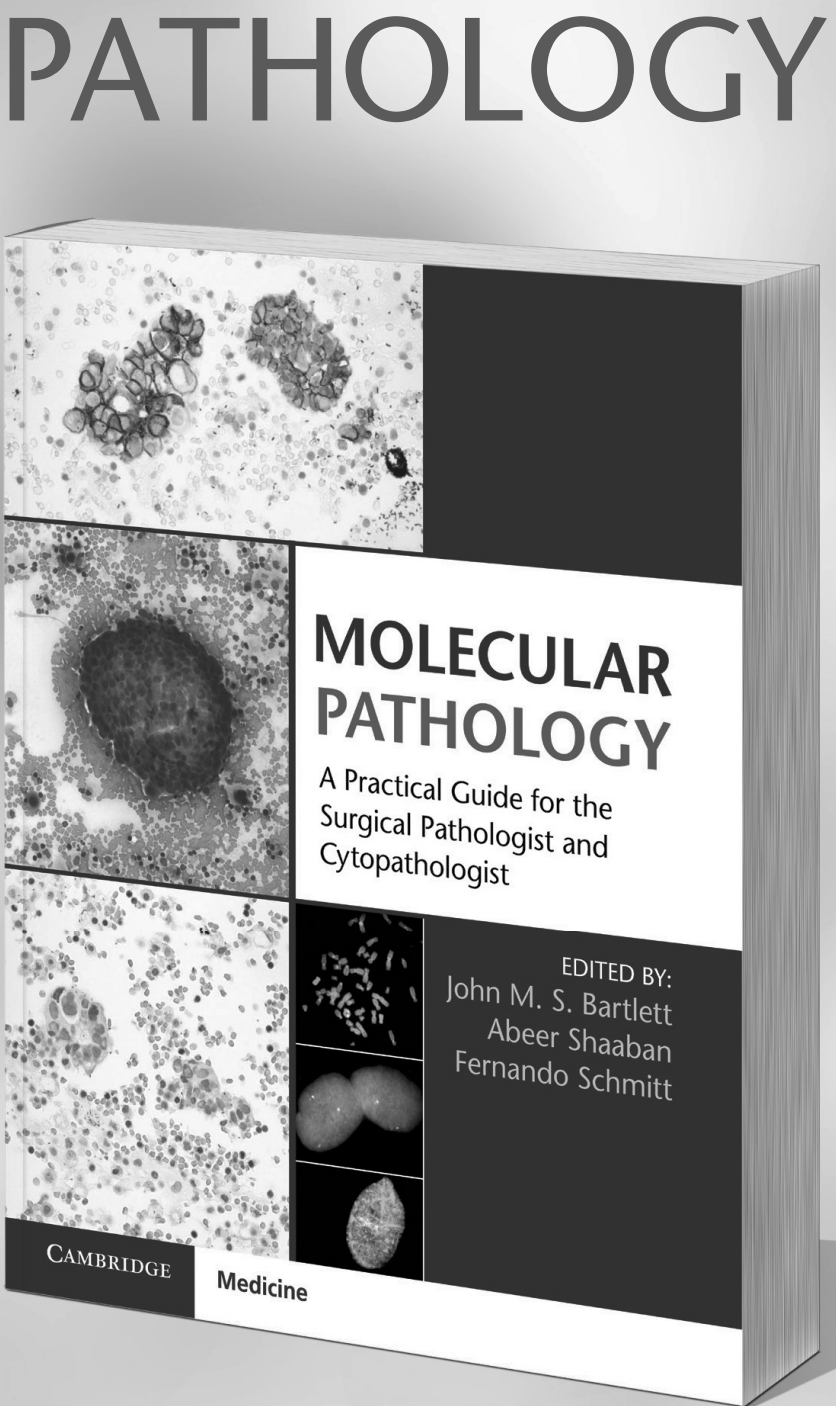

Print/Online Bundle

414 pages / 86 color illus. 38 tables

9781107443464 / \$135.00 / f84.99
This practical manual provides a comprehensive yet concise guide to state-of-the-art molecular techniques and their applications. It starts with an overview of the essential principles of molecular techniques, followed by separate chapters detailing the use of these techniques in particular tissues and organs, and describing recommended treatment plans. Each chapter covers the tests available, their advantages, limitations, and use as diagnostic and prognostic tools, with key learning points at the end of each topic. Using both histologic and cytologic samples, it discusses how to interpret test results in a pathologic context and enables trainees and practicing pathologists to gain an in-depth understanding of molecular diagnostic techniques and how to incorporate them into routine diagnostic practice. Aiding the daily practice of refining diagnosis, as well as offering a didactic approach, this book is an essential reference for practicing pathologists and cytopathologists as well as trainees in pathology.

- Offers a system-specific molecular approach in tissues and cytological preparations and covers current and future trends in molecular pathology to familiarize pathologists and cytopathologists with molecular diagnostic and prognostic criteria

- Describes the application of molecular techniques in diagnostic histopathology, cytopathology and clinical management

- Each chapter ends with a set of key learning points, offering a summary as well as a learning tool to surgical pathologists and cytopathologists 
An Official Publication of the Society for Healthcare Epidemiology of America

\section{EDITOR}

Suzanne F. Bradley, MD • Ann Arbor, MI

\section{DEPUTY EDITOR}

Carol Chenoweth, MD • Ann Arbor, MI

\section{SENIOR ASSOCIATE EDITORS}

C. Glen Mayhall, MD • Galveston, TX

Gina Pugliese, RN, MS • Chicago, IL

William Schaffner, MD • Nashville, TN

\section{ASSOCIATE EDITORS}

Lindsay E. Nicolle, MD • Winnipeg, Manitoba

Trevor C. Van Schooneveld, MD • Omaha, NE

David Weber, MD, MPH $\bullet$ Chapel Hill, NC

\section{STATISTICS CONSULTANTS}

Jon P. Furuno, $\mathrm{PhD} \bullet$ Portland, OR

Jessina C. McGregor, PhD • Portland, OR

\section{MANAGING EDITOR}

Gennifer Levey • New York, NY

\section{PAST EDITORS}

Infection Control

Richard P. Wenzel, MD, 1980-1987 (vols. 1-8)

Infection Control \& Hospital Epidemiology

Richard P. Wenzel, MD, 1988-1992

(vols. 9-13)

Michael D. Decker, MD, 1993-2001 (vols. 14-22)

Barry M. Farr, MD, 2002-2004 (vols. 23-25)

William R. Jarvis, MD, 2005-2006 (vols. 26 and 27)

EDITORIAL ADVISORY BOARD

Deverick Anderson, MD, MPH • Durham, NC
Anucha Apisarnthanarak, MD • Pratumthani, Thailand

Lennox Archibald, MD, FRCP • Alachua, FL

Shailen Banerjee, PhD • Atlanta, GA

Elise M. Beltrami, MD, MPH • Atlanta, GA

Jo Anne Bennett, RN, PhD • New York, NY

David Birnbaum, PhD, MPH • Sidney, BC

Marc Bonten, MD • Utrecht, Netherlands

Christian Brun-Buisson, MD • Creteil, France

John P. Burke, MD • Salt Lake City, UT

David P. Calfee, MD, MS • New York, NY

Yehuda Carmeli, MD, MPH • Tel Aviv, Israel

Donald E. Craven, MD • Burlington, MA

Christopher Crnich, MD, MS • Madison, WI

Erika D’Agata, MD, MPH • Boston, MA

Daniel Diekema, MD • Iowa City, IA

Erik Dubberke, MD, MSPH • St. Louis, MO

Charles E. Edmiston, Jr., PhD • Milwaukee, WI

Mohamad Fakih, MD, MPH • Grosse Pointe Woods, MI

Petra Gastmeier, MD • Berlin, Germany

Jeffrey Gerber, MD, PhD • Philadelphia, PA

Dale N. Gerding, MD • Hines, IL

Donald A. Goldmann, MD • Boston, MA

Nicholas Graves, $\mathrm{PhD} \bullet$ Brisbane, Australia

Donna Haiduven, RN, PhD, CIC • Tampa, FL

Anthony D. Harris, MD, MPH • Baltimore, MD

Elizabeth Henderson, PhD • Calgary, AB

David K. Henderson, MD • Bethesda, MD

Loreen A. Herwaldt, MD • Iowa City, IA

Peter N. R. Heseltine, MD • Brea, CA

John A. Jernigan, MD, MS • Atlanta, GA

Mini Kamboj, MD • New York, NY
Carol A. Kauffman, MD • Ann Arbor, MI

James T. Lee, MD, PhD • St. Paul, MN

L. Clifford McDonald, MD • Atlanta, GA

Allison McGeer, MD • Toronto, ON

Leonard A. Mermel, DO, ScM • Providence, RI

Robert R. Muder, MD • Pittsburgh, PA

Linda Mundy, MD • Collegeville, PA

Joseph M. Mylotte, MD, CIC • Buffalo, NY

Jan Evans Patterson, MD • San Antonio, TX

David A. Pegues, MD • Philadelphia, PA

Didier Pittet, MD, MS • Geneva, Switzerland

Isaam Raad, MD • Houston, TX

Manfred L. Rotter, MD, DipBact $\bullet$ Vienna, Austria

William A. Rutala, PhD, MPH • Chapel Hill, NC

Lisa Saiman, MD, MPH • New York, NY

Sanjay Saint, MD, MPH • Ann Arbor, MI

Sorana Segal-Maurer, MD • Flushing, NY

Lynne M. Sehulster, PhD • Atlanta, GA

John A. Sellick, DO • Amherst, NY

Andrew E. Simor, MD • Toronto, ON

Philip W. Smith, MD • Omaha, NE

Kurt Stevenson, $\mathrm{MD}, \mathrm{MPH} \bullet$ Columbus, $\mathrm{OH}$

Nimalie Stone, MD • Atlanta, GA

Thomas Talbot, MD, MPH • Nashville, TN

Paul Tambyah, MBBS • Singapore

William Trick, MD • Chicago, IL

Antoni Trilla, MD, PhD • Barcelona, Spain

Robert A. Weinstein, MD • Chicago, IL

Andreas Widmer, MD, MS • Basel, Switzerland

Marcus Zervos, MD • Detroit, MI
Infection Control \& Hospital Epidemiology (ISSN 0899-823X) is published monthly by Cambridge University Press, One Liberty Plaza, New York, NY 10006, USA.

\section{Editorial Office}

Communications should be addressed to the Editor, Infection Control \& Hospital Epidemiology, One Liberty Plaza, New York, NY 10006 (email: iche.managingeditor@cambridge.org. Contributors should consult the Instructions for Contributors, which is available at the journal's Web site.

\section{Advertising}

Please direct advertising inquiries to M. J. Mrvica Associates, 2 West Taunton Avenue, Berlin, NJ 08009 (e-mail: mjmrvica@mrvica.com; telephone: 856-768-9360, fax: 856-753-0064). Publication of an advertisement in Infection Control \& Hospital Epidemiology does not imply endorsement of its claims by the Society for Healthcare Epidemiology of America, by the Editor, or by Cambridge University Press.

\section{Permissions}

Articles may be copied or otherwise reused without permission only to the extent permitted by Sections 107 and 108 of the US Copyright Law. Permission to copy articles for personal, internal, classroom, or library use may be obtained from the Copyright Clearance Center (http://www.copyright.com, email: info@copyright.com). For all other uses, such as copying for general distribution, for advertising or promotional purposes, for creating new collective works, or for resale, please contact Cambridge University Press. Full details may be found at: www.cambridge.org/about-us/rights-permissions.

\section{Subscriptions}

The individual subscription rate for 2017 is $\$ 247$. Individuals have the option to order directly from Cambridge University Press. Institutional print + electronic and e-only subscriptions are available from Cambridge University Press and include unlimited online access; rates are tiered according to an institution's type and research output and may be reviewed at the journal's CJO homepage: cambridge.org/ICHE.

Please direct subscription inquiries and requests for back issues to Customer Services at Cambridge University Press, e-mail: subscriptions_newyork@ cambridge.org (USA, Canada, and Mexico) or journals@cambridge.org (outside of USA, Canada, and Mexico).

Postmaster: Send address changes to Infection Control \& Hospital Epidemiology, Cambridge University Press, One Liberty Plaza, New York, NY 10006 USA. 


\section{About the cover:}

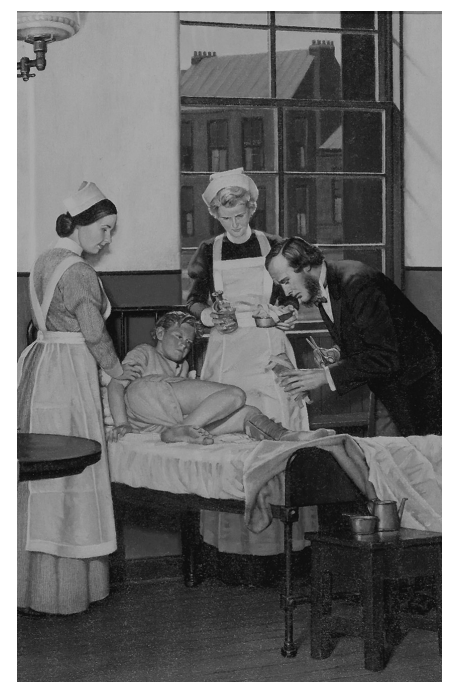

The cover format of each volume of Infection Control \& Hospital Epidemiology honors one of the many professionals throughout history who recognized not only how disease might be spread but also how the principles of epidemiology could be applied to reduce healthcareassociated infections.

Joseph Lister (1827-1912) was born to a Quaker family in the outskirts of London. His father, Joseph Jackson Lister, worked as a wine merchant by day and pursued the study of optics as a hobby. His work helped found modern microscopy, for which he was elected to the Royal Academy in 1832.

Young Lister decided to become a surgeon at an early age. Due to his religious affiliation, Lister was barred from attending older universities of greater prestige and settled upon study at the University of London, from which he received his medical degree and Fellowship in the Royal Academy of Surgeons. Lister moved to Edinburgh in 1853 to work under Mr. Syme, one of the preeminent British surgeons of the day. In Edinburgh, Lister made important observations on the pathogenesis of inflammation. He also gained a wife, Syme's daughter, Agnes, but in doing so had to become a member of the Church of England. Agnes worked closely beside Lister for many years, recording his experiments in great detail.

By 1856, Lister assumed professorship in surgery at the University of Glasgow, where he began to develop his principles of antiseptic surgery. At the time, surgical morality rates from sepsis ranged from $23 \%$ to $60 \%$, and it was assumed that putrefaction and purulent infection of wounds originated from tainted air. Based on the work of his colleague, Louis Pasteur, Lister performed a series of meticulous experiments in which he used antiseptics and developed optimal wound dressing techniques that focused on keeping wounds clean rather than excluding air. Lister traveled widely in the United Kingdom, Europe, and the United States promoting his wound-care techniques. He returned briefly to Edinburgh before assuming the Chair of Clinical Surgery at King's College in London. In 1891, Lister became a Founder of the British Institute for Preventive Medicine, the first academic medical research institute in the United Kingdom. He served as the Institute's President, and the organization was ultimately renamed in his honor. Lister served as President of the Royal Society of London and was appointed to the House of Lords. After his death, Lord Lister chose not to be buried in Westminster Abbey but rather was laid to rest next to his wife. 